\title{
Investigation of transient sea level rise impacts on water quality of unconfined shallow coastal aquifers
}

\author{
A. Ranjbar $^{1,2} \cdot$ C. Cherubini ${ }^{3} \cdot$ A. Saber ${ }^{4}$
}

Received: 17 July 2019 / Revised: 2 February 2020 / Accepted: 10 February 2020

(c) Islamic Azad University (IAU) 2020

\begin{abstract}
This study analyzes the impacts of $1 \mathrm{~m}$ gradual and instantaneous sea level rise combined with pumping activity on seawater wedge toe location in a shallow coastal aquifer located in the southern shores of the Caspian Sea. The gradual sea level rise scenario investigates the transition variation of seawater wedge toe due to linear and parabolic between the years 2015 and 2100. Moreover, the maximum value of saltwater intrusion due to variations in hydraulic conductivity and aquifer's recharge rates is analyzed and compared with flux-controlled and head-controlled boundary condition systems. A tree model is also applied to develop a linear regression between the sea level rise and aquifer parameters derived from different real coastal aquifers in the literature. The results indicate that $1 \mathrm{~m}$ gradual sea level rise in the study area by the end of the year 2100 considering all 1320 pumping wells leads to a $6.5 \%$ depletion of freshwater volume. The results also show that the peak saltwater intrusion rate during nonlinear gradual sea level rise rises with increasing the aquifer depth and horizontal hydraulic conductivity and the time to reach the saltwater intrusion peak rate considering the current recharge rate of an aquifer is about $48 \mathrm{~m}$. The maximum saltwater intrusion lengths estimated by the tree model are $48 \mathrm{~m}$ and $10.42 \mathrm{~m}$ for head-controlled and flux-controlled boundary conditions, respectively, indicating that the saltwater intrusion in the aquifer due to instantaneous seal level rise is closer to head-controlled boundary conditions.
\end{abstract}

Keywords Saltwater intrusion $\cdot$ Gradual sea level rise $\cdot$ Head-controlled system $\cdot$ Flux-controlled system

\section{Introduction}

Groundwater supplies are usually the main freshwater source in coastal zones around the globe. However, these limited freshwater resources are typically subjected to seawater

Editorial responsibility: Ta Yeong Wu.

Electronic supplementary material The online version of this article (https://doi.org/10.1007/s13762-020-02684-2) contains supplementary material, which is available to authorized users.

A. Ranjbar

aranjbar@mail.kntu.ac.ir

1 Department of Civil Engineering, K. N. Toosi University of Technology, Tehran, Iran

2 University of Queensland, Brisbane, Australia

3 Department of Physics and Earth Sciences, University of Ferrara, via Saragat, 44122 Ferrara, Italy

4 Department of Civil and Environmental Engineering and Construction, University of Nevada, Las Vegas, Las Vegas, NV, USA intrusion (Loáiciga et al. 2012; Werner et al. 2013; Sharip et al. 2019). Global warming effects such as sea level rise (SLR) and tidal fluctuations can result in increased saltwater intrusion into aquifers, significantly affecting the quality of extracted groundwater ( $\mathrm{Li}$ et al. 2001; Pool et al. 2014; Sefelnasr and Sherif 2014; Kuchaksaraei et al. 2019). Recent studies have predicted an SLR value of between 20 and $82 \mathrm{~cm}$ by the year 2100, indicating an extensive inundation of coastal regions (Vermeer and Rahmstorf 2009; IPCC 2013). Langevin and Dausman (2005) anticipated that an SLR of $0.5 \mathrm{~m}$ in Florida's coastal aquifers would result in $1.5 \mathrm{~km}$ increase in seawater wedge toe penetration in Broward County's unconfined aquifer, whereas the same SLR would result in about $0.4 \mathrm{~km}$ saltwater intrusion in the Nile Delta's confined aquifer. Carretero et al. (2013) numerically simulated the SLR in Partido de La Costa, Argentina. Their simulations based on flux-controlled and head-controlled boundary conditions revealed that an SLR of $1 \mathrm{~m}$ can result in $200 \mathrm{~m}$ and $38 \mathrm{~m}$ increase in seawater intrusion (SWI) in Partido de La Costa's unconfined aquifer, respectively. 
These differences in SWI during the gradual SLR confirm the major overshoot impact occurred in unconfined aquifers (Morgan et al. 2015). Lu et al. (2015) reported that considering a constant-head boundary during an SLR can result in an SWI increase more than the constant-flux inland boundaries. Previous studies have reported that the SLR can be a natural threat, particularly when combined with storm surges and over-extraction, leading to a significant SWI in coastal aquifers with flat land slopes (Uddameri et al. 2014; Hussain and Javadi 2016).

Werner and Simmons (2009) found on an analytical basis that head-controlled systems, where the groundwater table is fixed, for example, by drains, are particularly affected by sea level rise.

They highlighted that neglecting the SLR effects, particularly in flat shorelines, could lead to a substantial underestimation of both SWI length and freshwater flux.

Webb and Howard (2011) considered a numerical approach to the analytical work carried out by Werner and Simmons (2009) that identified the driving mechanisms of saltwater migration for such head-controlled systems. They investigated the impacts of hydraulic conductivity distribution, recharge rate, and effective porosity on the transient movement of saline zone. Their results demonstrated that in an aquifer having a high porosity and a high hydraulic conductivity-to-recharge ratio, it would take several centuries for the saltwater wedge toe location to reach equilibrium after an SLR.

Abd-Elhamid and Javadi (2011) developed a transient density-dependent finite element model to investigate the individual and combined effects of likely sea level rise and over-pumping on seawater intrusion. They considered three scenarios: rise in sea levels due to climate change, decline in groundwater table due to over-pumping and combination of sea level rise and over-pumping. The results show that the rise in the sea level moved the transition zone inland by about $5 \%$ and the combination of sea level rise and overpumping resulted in a further inland movement of the transition zone (about 8\%).

Hussain and Javadi (2016) numerically examined the long-term impacts of prompt and steady SLRs on saltwater intrusion in shallow unconfined aquifers with sloped land surfaces using the SUTRA (Voss and Provost 2010) model. Their simulations for inundations due to steady SLRs revealed that SWI fluxes were higher in flat shorelines compared to steep-slope land surfaces. Chesnaux (2016) employed four analytical solutions to evaluate the vulnerability of unconfined steep-slope aquifers to SWI due to SLR. This study showed that the SLR could significantly affect travel time and freshwater quantity of aquifers located in flatter coasts. However, this study also showed that the land slope has a limited impact on SWI in a hypothetical aquifer with constant-head inland boundary conditions.
Results of Ketabchi et al.'s (2014) study assuming a sharp interface between saline and fresh waters also revealed that land surface inundation could have a significant influence on the shape of freshwater lenses in small heterogeneous island aquifers. They also reported that the sensitivity of freshwater lens shape to SLR was less than hydraulic conductivity and recharge rate. Ketabchi et al. (2016) studied the effects of SLR on the saltwater wedge location in small islands and coastal aquifers by means of analytical and numerical models. They showed that SLR could have a significant effect on the seawater intrusion length in aquifers with land surface slopes $\leq 1 \%$.

Several studies have attempted to evaluate the impacts of aquifer's hydrogeological properties on SWI using long-term SLR simulations (Watson et al. 2010; Webb and Howard 2011; Michael et al. 2013; Ferchichi et al. 2018). Generally, the effects of SLR and recharge rate on SWI could be more pronounced in arid coastal zones, particularly during dry seasons with low precipitation (Ranjabr and Mahjouri 2019).

Chang et al. (2011) found that in confined aquifers, near steady state, with constant freshwater fluxes, an increase in sea level would cause the piezometric rise in rechargelimited systems, called lifting process, which would mitigate the saltwater intrusion. In unconfined aquifers, this lifting was less effective.

However, investigations by Michael et al. (2013) showed that in topography-limited systems, where the water table is close to the land surface and would intersect it in case of water table rise, sea level rise would mainly result in enhanced surface runoff and therefore limited rise in groundwater levels. Thus, the lifting effect would no longer counteract the progression of the saltwater intrusion. Moreover, they stated that approximately $70 \%$ of world coastlines may be topography-limited.

Green and MacQuarrie (2014) performed a numerical simulation using the SEAWAT model to evaluate the relative influence of SLR, recharge rate, and pumping activity on the SWI in Richibucto aquifer, Canada. They concluded that the effects of decreased recharge were mostly considerable at shallow to intermediate depths, whereas the SLR effects were significant in deeper layers of the transition zone. They also found that the effects of excessive pumping rates were limited to the vicinity of production wells.

Xiao et al. (2018) established a baseline model based on FEMWATER to simulate the transient variation of SWI of coastal east-central Florida (USA) under three SLR scenarios by 2080 . The study results showed that SWI would be significant if SLR is high $(120 \mathrm{~cm})$.

Xiao and Tang (2019) used SEAWAT for quantifying the effect of storm surge and instantaneous sea level rise on time-variant extent of the migrated saltwater in the Florida Atlantic coast between 2004 and 2024. The 
outcome of their study indicates the high effect of SLR on SWI into the surficial aquifer.

Xiao and Tang (2019) also used the SEAWAT model to predict the SWI rate due to SLR in the karstic aquifer of Woodville, Florida.

Yang et al. (2019) implemented HydroGeoSphere (Brunner and Simmons 2012) code to predict the combined effect of wire construction and mean sea level rise level on SWI. They concluded that increasing the weir construction height as well as MSLR can lead to an increase in the new ponding area and corresponding SWI.

Stiger et al. (2014) analyzed the combined SLR and recharge rate impacts on SWI in three Mediterranean aquifers in Portugal, Spain, and Morocco by means of FEFLOW (Diersch 2005) and FEM301(Kiraly 1985). Their results showed that although an SLR of $1 \mathrm{~m}$ in all three aquifers could noticeably influence the SWI and piezometric heads, the effects of reduced recharge rates and increased pumping rates on SWI were substantially greater. Their results confirmed the dominant effects of over-extraction on transient SWI in coastal aquifers which combined with SLR could threaten the fresh groundwater resources (Anderson and Al-Thani 2016).

Colombani et al. (2016) developed a three-dimensional density-dependent groundwater flow model using SEAWAT to study the SLR impact on SWI quantity by 2050 in an unconfined coastal aquifer in the Po Delta, Italy. They showed that the projected SLR and inverted hydraulic gradient due to over-pumping were the major sources of aquifer salinization.

Hence, a variety of factors including land surface slope, shoreline slope, boundary conditions, recharge rate, aquifer permeability, and extraction rate can affect the SWI in coastal aquifers. However, most studies considering the simultaneous effects of these factors on SWI during ISLR and GSLR are not carried out on real case studies but only on hypothetical aquifers.

Furthermore, water extraction management practices that need to be adopted in order to control the SWI during an SLR should be further investigated.

The current study investigates the effects of $1 \mathrm{~m}$ ISLR and GSLR on total dissolved solids (TDS) concentration and freshwater quantity based on data observed from 2012 to 2016, a shallow unconfined aquifer. On the basis of the information obtained from observed hydraulic heads, pumping rates, measured TDS concentrations, topography, resistivity maps, sources-sinks, land surface slope, and bed slope, a SEAWAT variable-density flow model has been developed to simulate the SWI during transient $1 \mathrm{~m}$ SLR. Variations in groundwater level and aquifer's freshwater volume after $1 \mathrm{~m}$ ISLR are quantified and compared with head-controlled (HC) and flux-controlled (FC) boundary condition systems. In addition, pumping management practices for controlling
SWI and its effects on aquifer's salinity due to a GSLR are presented. Finally, on the basis of the information obtained from the literature for different aquifers, an M5 tree model is used to develop a piecewise linear regression model between the SLR and SWI and is subsequently compared with the results of SEAWAT model.

The current study investigates the effects of SLR on TDS concentration and groundwater quantity in Talar aquifer based on data observed from 2012 to 2016, in the southern shores of the Caspian Sea between 2014 and 2015.

\section{Materials and methods}

\section{Study area}

Talar aquifer is located in Mazandaran coastal region, northern Iran, and lies between latitudes $36^{\circ} 43^{\prime}$ and $37^{\circ} 30^{\prime} \mathrm{N}$ and longitudes $52^{\circ} 22^{\prime}$ and $53^{\circ} 42^{\prime} \mathrm{E}$. The aquifer is bounded to the north by the Caspian Sea, to the south by no-flow boundary conditions, and to the east and west by Siahrood and Babolrood rivers, respectively (Fig. 1).

The total area of Talar aquifer is about $776 \mathrm{~km}^{2}, 25 \%$ of which is covered by agricultural lands. There are approximately 29,584 shallow pumping wells in the region (Fig. 1c), extracting freshwater with rates of 195 million $\mathrm{m}^{3}$ year $^{-1}$, 156 million $\mathrm{m}^{3}$ year $^{-1}$, and 30 million $\mathrm{m}^{3}$ year $^{-1}$ for agricultural, industrial, and domestic purposes, respectively. The maximum pan evaporation is about $1483 \mathrm{~mm}_{\text {year }}{ }^{-1}$ in the northeastern parts, where the water table is shallow. The aquifer is recharged by precipitation and leakage from Siahrood and Babolrood rivers, flowing from south to north of the aquifer (Fig. 1b). The average annual precipitation near the shoreline is $761 \mathrm{~mm}$, and the recharge rate by agricultural irrigation is estimated between 48.26 and 327.34 million $\mathrm{m}^{3}$ year $^{-1}$.

The major part of the aquifer consists of fine-grained deposits with an average thickness of about $150 \mathrm{~m}$. The geology of the study area is mainly characterized by conglomerate sediments, with admixtures of fine-grained sand, silt, and gravel, with a high permeability particularly in northern areas (Fig. 2a). The aquifer is generally unconfined (70\%) in the Talar region; however, there are thin clay and silt layers in the middle part (Fig. 2a and Supplementary Fig. S1), and hence, in the middle part it is semiconfined. Vertical profiles and thickness of different layers in the study site were determined using 159 deep boreholes (Khairy and Janardhana 2016). In addition, resistivity geophysical surveys of subsurface layers up to $100 \mathrm{~m}$ depth were applied to determine the quaternary clay content and for bedrock mapping. In the vicinity of Babolrood River, the electrical resistivity of water is ranging between 2 and $80 \Omega$ indicating the high content of salinized deposits (Fig. 2a). 
The upper layers of the aquifer are typically characterized by coarse grain alluvial, whereas the lower layers are generally composed of coarse sand and gravel underlain by silt and clay. The permeability of the aquifer ranges between 1.6 and $3.2 \mathrm{~m}^{2}$ day $^{-1}$ from east to west (Fatemi and Ataie-Ashtiani 2008). A total number of 14 deep wells and 27 shallow wells were drilled along the shoreline to measure the groundwater level and TDS concentration fluctuations (Khairy and Janardhana 2016).

The aquifer thickness gradually increases from $10 \mathrm{~m}$ in north and northeastern areas (near the shoreline) to about $48 \mathrm{~m}$ in southern parts. The depth to the water table in

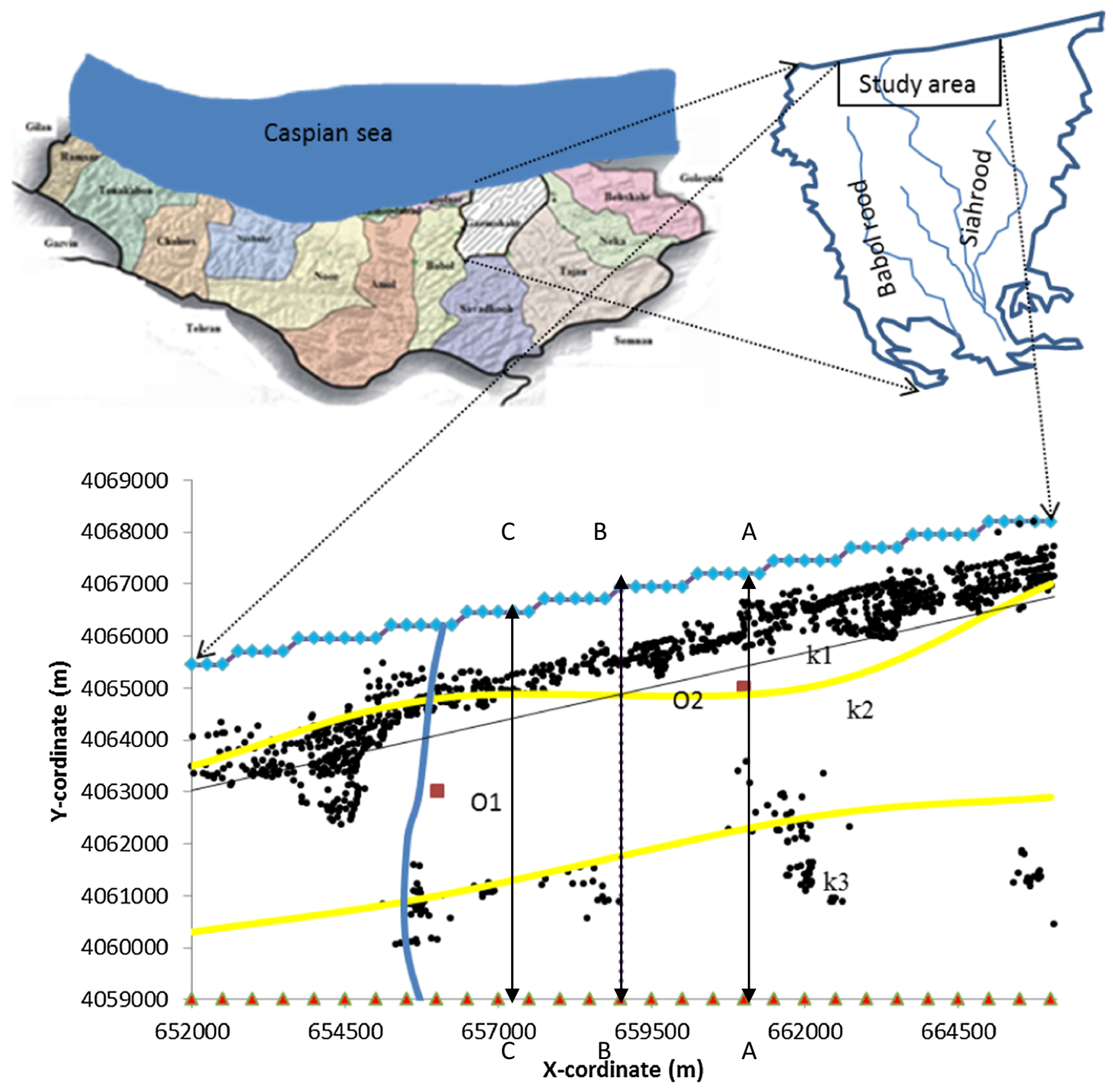

\begin{tabular}{|lll|}
\hline- & Pumping well & Observation well \\
$\wedge \quad$ General head & Constant head \\
Hydraulic conductivity boundary & Hydraulic conductivity boundary \\
Drain & S-S Cross section \\
\hline
\end{tabular}

Fig. 1 Boundary conditions of the study area (Ranjbar and Ehteshami (2019) 


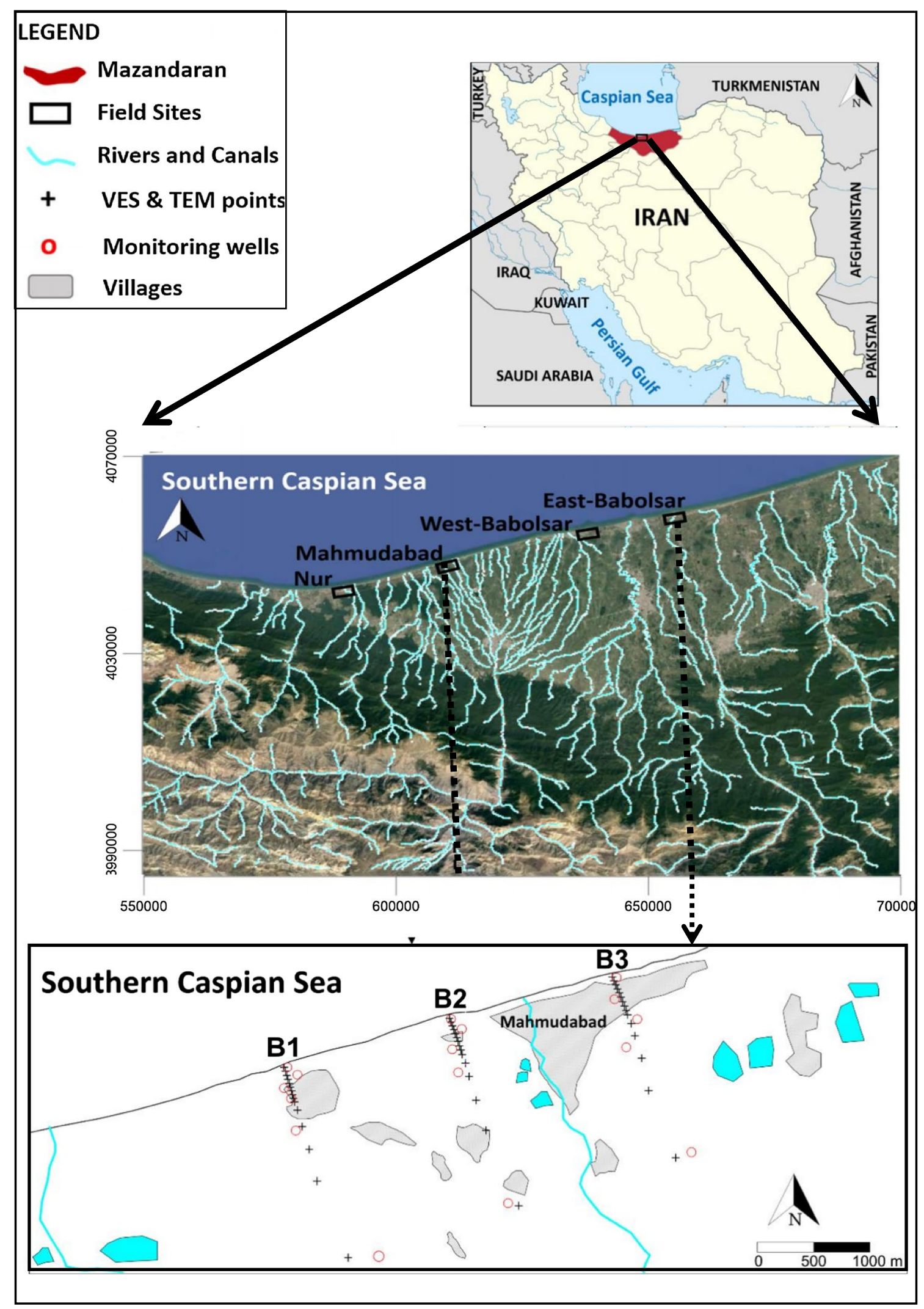

Fig. 1 (continued) 


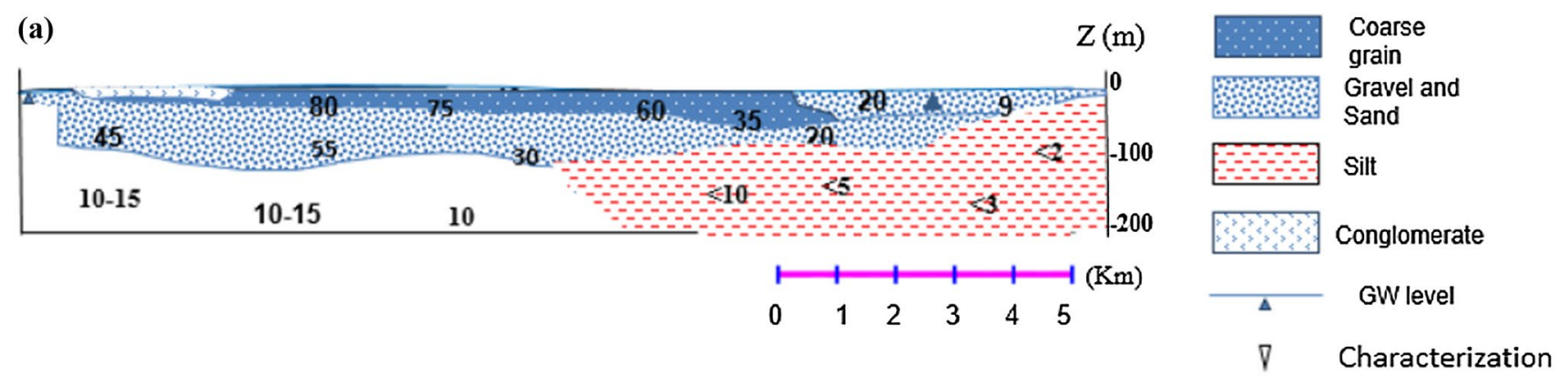

(b)

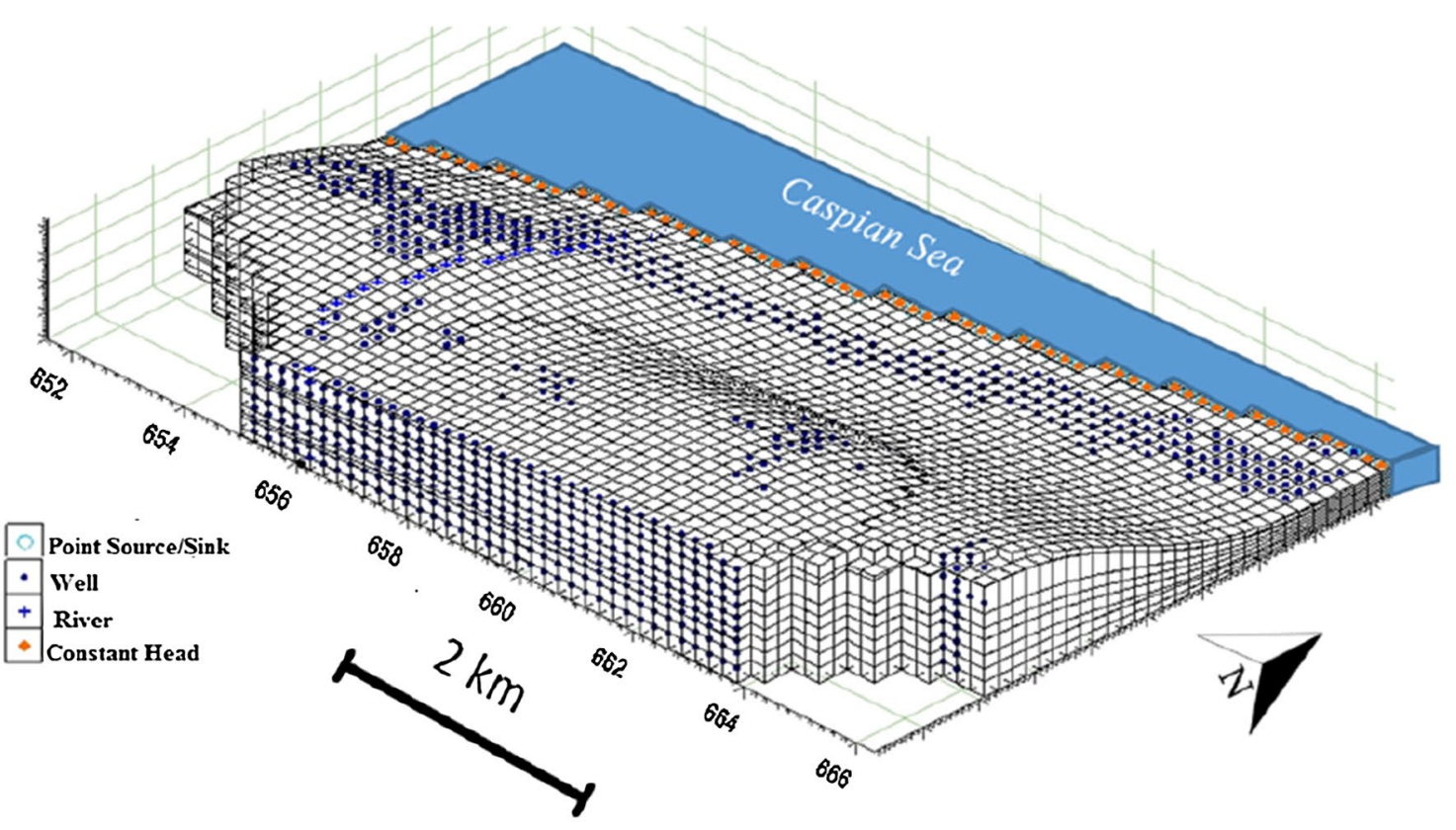

Fig. 2 a Generalized cross section S-S of the unconfined aquifer and resistivity values. b The three-dimensional model grid

southern parts varies between 20 and $40 \mathrm{~m}$ during pre-monsoon, whereas it reaches about $2 \mathrm{~m}$ near the shoreline.

\section{Model setup}

\section{Groundwater modeling package}

This study uses SEAWAT, a 3D finite difference numerical model Langevin and Dausman (2005), to simulate the variable-density groundwater flow and SWI in Talar aquifer. The SEAWAT (Guo and Langevin 2002) model used in this study incorporates the MODFLOW-2000 (Harbaugh 2005) and MT3DMS (Zheng and Wang 1999), in the GMS 10.2 package.

The variable-density groundwater flow equation solved by SEAWAT is formulated using the equivalent freshwater head as the principal dependent variable. In this form, the equation is similar to the constant-density groundwater flow equation solved by MODFLOW.

\section{Numerical modeling of SLR scenarios}

\section{Modeling of groundwater level}

The spatial and temporal TDS variations in the study area (Fig. 1c) were simulated by means of a density-dependent solute transport model in an unconfined aquifer. The study area with dimensions of $16 \mathrm{~km}$ (length) $\times 11 \mathrm{~km}$ (width) was discretized into $250 \mathrm{~m} \times 250 \mathrm{~m}$ cells, respectively, in $X$ and $Y$ directions. On the basis of the geostratigraphical asset (see Supplementary Fig. S1), the study area was discretized into 10 layers with varying thicknesses in the $Z$ direction (Fig. 2b).

Considering the first layer's top as the ground surface, the maximum and minimum depth in the southern (noflow boundary conditions) and northern (Caspian Sea) 
boundaries, respectively, were assigned as $48 \mathrm{~m}$ and $10 \mathrm{~m}$. A simulation period of 5 years was considered for the transient conditions which were divided into 60 monthly time steps. The initial TDS values in the southern and northern boundaries were considered to be $0.2 \mathrm{~g} \mathrm{~L}^{-1}$ and $12.6 \mathrm{~g} \mathrm{~L}^{-1}$, respectively, representative of freshwater and seawater at these boundaries. The TDS concentration for Talarkia River and other active cells was assumed to be $0.2 \mathrm{~g} \mathrm{~L}^{-1}$. In the GSLR scenario, the northern (Caspian Sea) boundary was simulated using a time-variant specified head (CHD) package considering hydraulic heads between $8 \mathrm{~m}$ and $9 \mathrm{~m}$ varying with time. The initial heads in the study area were assigned on the basis of the measured hydraulic heads. The parallelism of the flow lines with respect to the lateral (left and right) boundaries indicated negligible flow rates from the lateral boundaries; thus, no-flow boundary conditions were considered for lateral sides.

A constant-head boundary condition $(h=18 \mathrm{~m})$ and $18,500 \mathrm{~m}^{2}$ day $^{-1}$ flow conductance were considered for the southern boundary to simulate the groundwater inflow to the system.

Talarkia River was simulated using the River package GMS 10.2 suite with an average stage of $18 \mathrm{~m}$ and a flow conductance of $4500 \mathrm{~m}^{2} \mathrm{day}^{-1}$ measured at the two river observation points $\left(\mathrm{O}_{1}\right.$ and $\mathrm{O}_{2}$ (Fig. 1c). In order to simulate the water extraction from the pumping wells, the total extraction rate of $14,770 \mathrm{~m}^{3}$ day $^{-1}$ was equally distributed to all 1320 wells in the study area. (Figures 2 and 3 show the location of the wells.)

Table 1 summarizes the ranges of different solute transport parameters used in the simulations.

\section{Modeling of solute transport}

A third-order total variation diminishing (TVD) numerical scheme was used to solve the concentration variations due to advection and dispersion in the MT3DMS model.

The groundwater flow equations were solved using MODFLOW-2000. During the parameter estimation using the forward technique, MODFLOW model was performed repeatedly and the model outputs were overwritten during subsequent runs. Model calibration was performed using PEST 13.0, and data from two observation wells (O1 and O2) located near the shoreline (Fig. 1) are used for the validation phase. The model was calibrated by means of observed hydraulic heads using horizontal hydraulic conductivities $\left(k_{i}\right)$. The observations from 2012 to 2014 and 2014 to 2015 were used for calibration and validation of groundwater heads, respectively, to predict TDS concentrations between the years 2015 and 2100 .

The SLR values used in this study are determined using a report by IPC (2001) which shows SLR of $0.65 \mathrm{~m}$ by 2100.

(b)
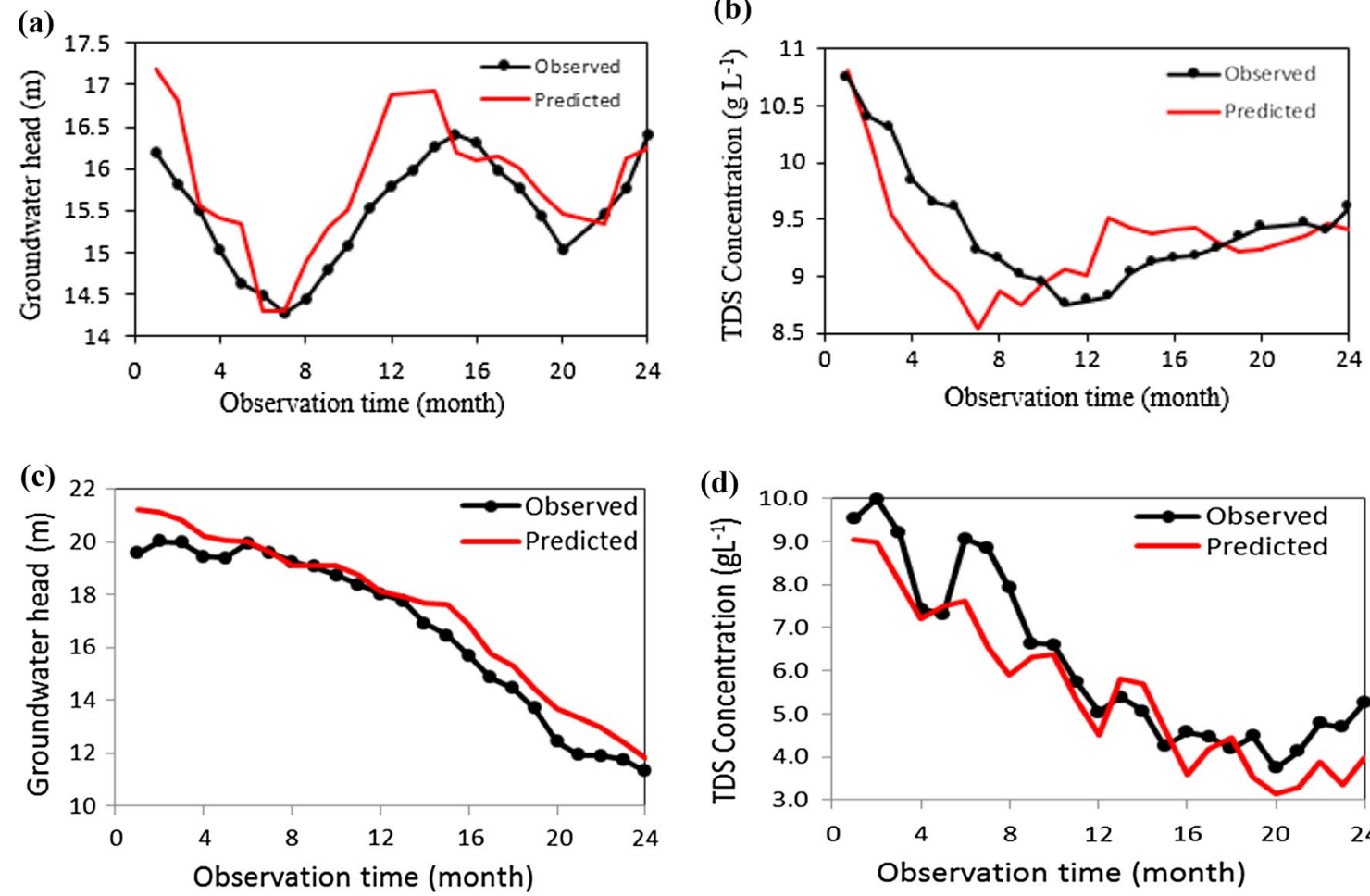

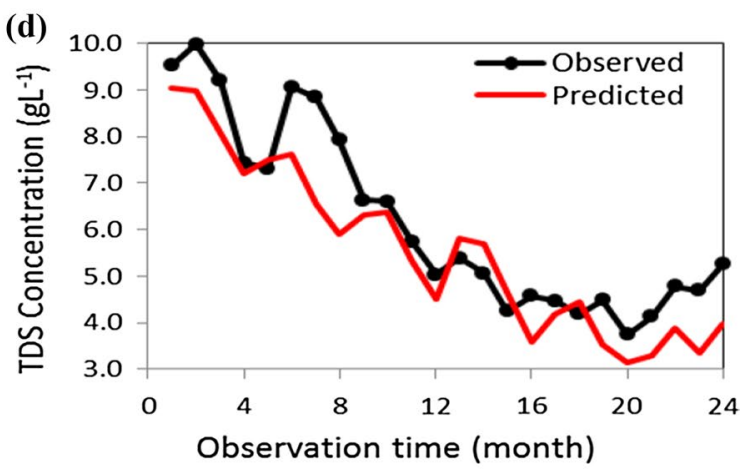

Fig. 3 Comparison of predicted model values for a groundwater head, and $\mathbf{b}$ TDS concentration with observed values at observation well $\mathrm{O}_{2}$ 
Table 1 Parameters used in the 3D solute transport model

\begin{tabular}{lll}
\hline Parameter & Range (unit) & $\begin{array}{l}\text { Number of } \\
\text { parameters }\end{array}$ \\
\hline Aquifer's thickness $(\mathrm{d})$ & $10-49^{\mathrm{b}}(\mathrm{m})$ & - \\
Shoreline slope $(-)$ & $0.06^{\mathrm{c}}(-)$ & 1 \\
Seawater density $\left(\rho_{s}\right)$ & $1015^{\mathrm{c}}\left(\mathrm{Kg} \mathrm{m}^{-3}\right)$ & 1 \\
Freshwater density of $\left(\rho_{o}\right)$ & $1000^{\mathrm{c}}\left(\mathrm{Kg} \mathrm{m}^{-3}\right)$ & 1 \\
Longitudinal dispersivity $\left(\alpha_{\mathrm{L}}\right)$ & $30-50^{\mathrm{c}}(\mathrm{m})$ & 1 \\
Transverse dispersivity $\left(\alpha_{\mathrm{T}}\right)$ & $4-10^{\mathrm{c}}(\mathrm{m})$ & 1 \\
Molecular diffusion coefficient $\left(D_{\mathrm{m}}\right)$ & $6 \times 10^{-7 \mathrm{c}}\left(\mathrm{m}^{2} \mathrm{~s}^{-1}\right)$ & 1 \\
Dynamic viscosity of water $(\mu)$ & $80-12086^{\mathrm{b}}\left(\mathrm{Kg} \mathrm{m}^{-1} \mathrm{~s}^{-1}\right)$ & 1 \\
Horizontal hydraulic conductivity $\left(k_{\mathrm{h}}\right)$ & $0.15-0.4^{\mathrm{a}}\left(\mathrm{m} \mathrm{day}^{-1}\right)$ & 3 \\
Effective porosity $(n)$ & $0.35^{\mathrm{c}}(-)$ & 1 \\
Specific storage $\left(S_{\mathrm{s}}\right)$ & $6 \times 10^{-4 \mathrm{~b}}(-)$ & 1 \\
Vertical anisotropy $(\lambda)$ & $0.1-0.5^{\mathrm{b}}(-)$ & 2 \\
\hline
\end{tabular}

aparameters used in calibration step

${ }^{b}$ Values obtained from Fatemi and Ataie-Ashtiani (2008)

${ }^{\mathrm{c}}$ Values obtained from Khairy and Janardhana (2016)

\section{Model calibration}

The southern flow boundary of $Q$ was considered as general head boundary (GHB) in which the conductance (8430 $\mathrm{m}^{2} /$ day) and elevation (about $19 \mathrm{~m}$ ) are constant and $Q$ is a function of the water stage in each stress period. The initial head of the domain was calculated using the natural neighbor interpolation in the two observation wells $\mathrm{O}_{1}$ and $\mathrm{O}_{2}$ (Fig. 1c). To reach the steady-state flow conditions, the model was run for a 200-year stress period.

In order to improve the model's efficiency, a sensitivity analysis was conducted to investigate the influence of different parameters on the accuracy of predicted hydraulic groundwater heads and TDS concentrations. After adjusting the hydraulic conductivity of different clusters during the model calibration process, the SEAWAT model was run in steady-state conditions to determine the location of transition and initial groundwater head. The model was simulated under different nonlinear variations of gradual SLR (GSLR) from 2015 to 2100.

According to IPCC (2003), the time-variant specified head for the Caspian Sea was increased in transient conditions from 11 to $12 \mathrm{~m}$ through monthly time steps during the period of 2015 to 2100 . In order to consider the parabolic SLR trend during the period of 2015 to 2100 , the simulated heads and TDS concentrations at the end of each monthly time step were assigned as initial conditions for the next subsequent step (Hussain and Javadi 2016). The inundated land surface in the GSLR scenario was simulated by considering shoreline and bed slopes of $6 \%$ and $1 \%$, respectively.

In order to decrease the discrepancies between the simulated and observed hydraulic heads, the water stage of the general head boundary (GHB) in the southern boundary was adjusted, since it is the key source of inflow within the aquifer. The hydraulic conductivity of this boundary was set constant, and flow rates were determined by the water level. The results of sensitivity analysis at the observation point $\mathrm{O}_{1}$ showed that $k_{1}$ (Fig. 1c) had a great influence on the hydraulic head, while $k_{3}$ (Fig. 1c) had a negligible effect on the head values. This is because $k_{1}$ is located near the coastline, and hence, the variation of $k_{1}$ led to variation in width and length of the transition zone. In order to enhance the model performance, small increments $0.5 \mathrm{~m} \mathrm{day}^{-1}$ was used for $k_{1}$ during the calibration process.

Due to small horizontal inhomogeneity of the sand and gravel layer across the major part of the study area (Fig. 2a and supplementary Fig. S1), a constant horizontal hydraulic conductivity was considered for the entire model.

\section{Model performance evaluations}

The model performance was evaluated by computing the root-mean-square error (RMSE) and percent relative error (RE) between the observed and simulated groundwater heads and TDS concentrations. RMSE was calculated as (Pillai et al. 2017):

$\mathrm{RMSE}=\left[\frac{\sum_{i=1}^{n}\left(X_{\mathrm{obs}}-X_{\mathrm{sim}}\right)^{2}}{n}\right]^{\frac{1}{2}}$,

where $X_{\text {obs }}$ is the observed groundwater head or TDS concentration, $X_{\text {sim }}$ is the predicted groundwater head or TDS concentration, and $\mathrm{n}$ is the number of observation wells (2) in the study area. 
The relative error $(R E)$ was calculated as (Pillai et al. 2017):

$\operatorname{RE}(\%)=\frac{\left|X_{\mathrm{obs}}-X_{\text {sim }}\right|}{X_{\mathrm{obs}}} \times 100$.

The error between the observed $\left(h_{\mathrm{obs}}\right)$ and simulated hydraulic heads $\left(h_{\text {sim }}\right)$ and salt concentration was calculated based on data from $n$ observation wells. Moreover, the rootmean-square error (RMSE) and the relative error $\left(\mathrm{RE}_{m}\right)$ between the observed maximum head $\left(h_{m}\right)$ and the simulated maximum head $\left(\hat{h}_{m}\right)$ indexes are used to calculate $\mathrm{RE}_{m}$.

Information obtained from the literature (Table 2 ) for different aquifers was used to develop a generic prediction model. To remove the scale impacts, dimensionless parameters were adopted to generate linear equations between SLR and $\Delta T 50$ (Pillai et al. 2017). To obtain a high correlation coefficient between input and output data, different dimensionless parameters were examined. Finally, the dimensionless parameters providing the best performance for the prediction model were of the form (Ketabchi et al. 2016):

$\mathrm{SLR}^{*}=\frac{\mathrm{SLR}}{W}$

$\Delta T 50^{*}=\frac{\Delta T 50}{L}$,

where SLR* represents the dimensionless SLR, $\Delta T 50^{*}$ represents the dimensionless SWI, $\Delta T 50^{*}$ is the further advancement of iso-concentration line $50 \%$, and $\mathrm{W}$ and $\mathrm{L}$ are aquifer depth and length, respectively.

Table 2 Summary of dimensionless SWI parameters under flux-controlled and head-controlled boundaries (Werner and Simmons 2009; Sefelnasr and Sherif 2014; Abd-Elhamid et al. 2016; Ketabchi et al. 2016; Abd-Elhamid et al. 2019)

\begin{tabular}{lllll}
\hline FC system & & & HC system & \\
\cline { 5 - 5 } SLR $/ W$ & $\Delta T 50 / L$ & & SLR $/ W$ & $\Delta T 50 / L$ \\
\hline 0.007 & 0.0003 & 0.01 & 0.003 \\
0.009 & 0.0004 & & 0.02 & 0.006 \\
0.0101 & 0.002 & 0.021 & 0.008 \\
0.021 & 0.004 & 0.021 & 0.0081 \\
0.02 & 0.007 & 0.1 & 0.03 \\
0.0035 & 0.009 & 0.0121 & 0.035 \\
0.03 & 0.011 & 0.03 & 0.09 \\
0.04 & 0.0105 & 0.02 & 0.105 \\
0.03 & 0.0109 & 0.05 & 0.11 \\
0.04 & 0.02 & 0.1 & 0.3 \\
0.05 & 0.04 & 0.02 & 0.35 \\
0.08 & 0.045 & 0.11 & 0.6 \\
0.03 & 0.06 & 0.0109 & 0.104 \\
0.11 & 0.14 & 0.02 & 0.085 \\
\hline
\end{tabular}

\section{Development of M5 tree}

Model trees (MT) solve nonlinear problems by dividing the input data into sub-categories and assigning a constant value or equation. For each sub-category, there is one equation that predicts the output corresponding to its input. The main preference of MT models versus other data-driven systems such as artificial neural networks (ANNs) is that they are able to develop a linear regression between model inputs and outputs. The M5 tree is one of the most popular tree-based models that assign a linear equation to each sub-category (Quinlan 2014). The M5 tree splits the input space into many subspaces considering its value and fits the best regression model to each subspace. The splitting process can be explained by the recursive traveling from the top of the tree to leaves regarding the decision role (see Supplementary material). The training data are examined for all nodes, and then the data are moved to the down of the tree. When the training samples reach the leave, the dividing process is finished, and the last value is considered as the target for prediction objects.

The M5 algorithm computes the standard deviation reduction index (SDR) for the partitioning of input area with the optimal structure of the tree (Frank et al. 2004) as follows (Pillai et al. 2017):

$\operatorname{SDR}=\operatorname{sd}(T)-\sum_{i} \frac{\left|T_{i}\right|}{|T|} \times \operatorname{sd}\left(T_{i}\right)$,

where $T=$ actual value of samples that reached the specific node, $T_{i}=$ value of samples after dividing the region into subregions, sd standard deviation, $\left|T_{i i}\right| \mid T=$ criterion for measuring the error after splitting the specific node. The partitioning process is carried out for all nodes and created many branches. The node can be selected as the dividing point if it has the small SD value for new inputs which meet threshold error value (generally 7\%). The prediction error is reduced with increasing the splitting process and as the tree grows deeper. Therefore, corresponding to the number of the training samples a stop criterion should be considered to stop growing a large tree. This process is named pruning where tree growth causes over-training and the complex tree cannot predict unseen data. The pruning step uses the Gini index which calculates the tree complexity corresponding to the generated error. If with a small change in the value of training set the structure of the tree is significantly changed, the tree cannot be considered as a smooth tree (Hastie et al. 2009). The smoothing criterion is to provide a tree that shows the lowest sensitivity on training data. The datadriven software for implementation of M5 tree in this study is WEKA developed by the University of Waikato, New Zealand (Garner 1995). 


\section{Results and discussion}

\section{Model calibration}

Figure 3 shows the hydraulic heads and TDS concentrations predicted by the model at $\mathrm{O}_{2}$ observation well with observed values at this station. A good agreement between real observations and model-predicted values for both parameters was obtained.

Hydraulic heads of the calibrated model by using the adjusted parameters (Fig. 3) highlight that there is a good match between the calculated and observed heads (correlation coefficient 0.85 ). The average RE and RMSE values for TDS concentrations were $4.6 \%$ and $0.38 \mathrm{~g} \mathrm{~L}^{-1}$, respectively, whereas these values for groundwater heads were $3.8 \%$ and $0.542 \mathrm{~m}$, respectively. Regarding the dimensions of domain, their values are identified satisfactory. Figure 7a, b, respectively, shows the predicted horizontal groundwater velocity vectors and TDS concentrations in the study area on February 28, 2020. As Fig. 4 shows, the main groundwater flow direction is from the south toward the north. However, the high number of pumping wells approximately located $1 \mathrm{~km}$ distance from the shoreline (Fig. 1c) could influence the flow patterns. As observed from Fig. 3b, water extraction from densely situated pumping wells in northwestern $(X<656,000 \mathrm{~m})$ and northeastern $(X>662,000 \mathrm{~m})$ resulted in northerly flow directions from the shoreline toward the pumping wells. Although due to the lower density of pumping wells in northern areas $(656,000 \mathrm{~m}<X<662,000 \mathrm{~m})$ the general flow trend is southerly, the magnitude of velocity vectors is noticeably small. This is due to the influence of groundwater over-extraction on flow directions, developing flow directions from the shoreline toward the densely situated wells, promoting the SWI into the freshwater aquifer. This is reflected in high TDS concentration zones (Fig. 4b). As Fig. 4b shows, high groundwater extractions
Fig. 4 Model predictions for a horizontal groundwater velocity vectors and TDS concentrations in the study area on February 28,2020

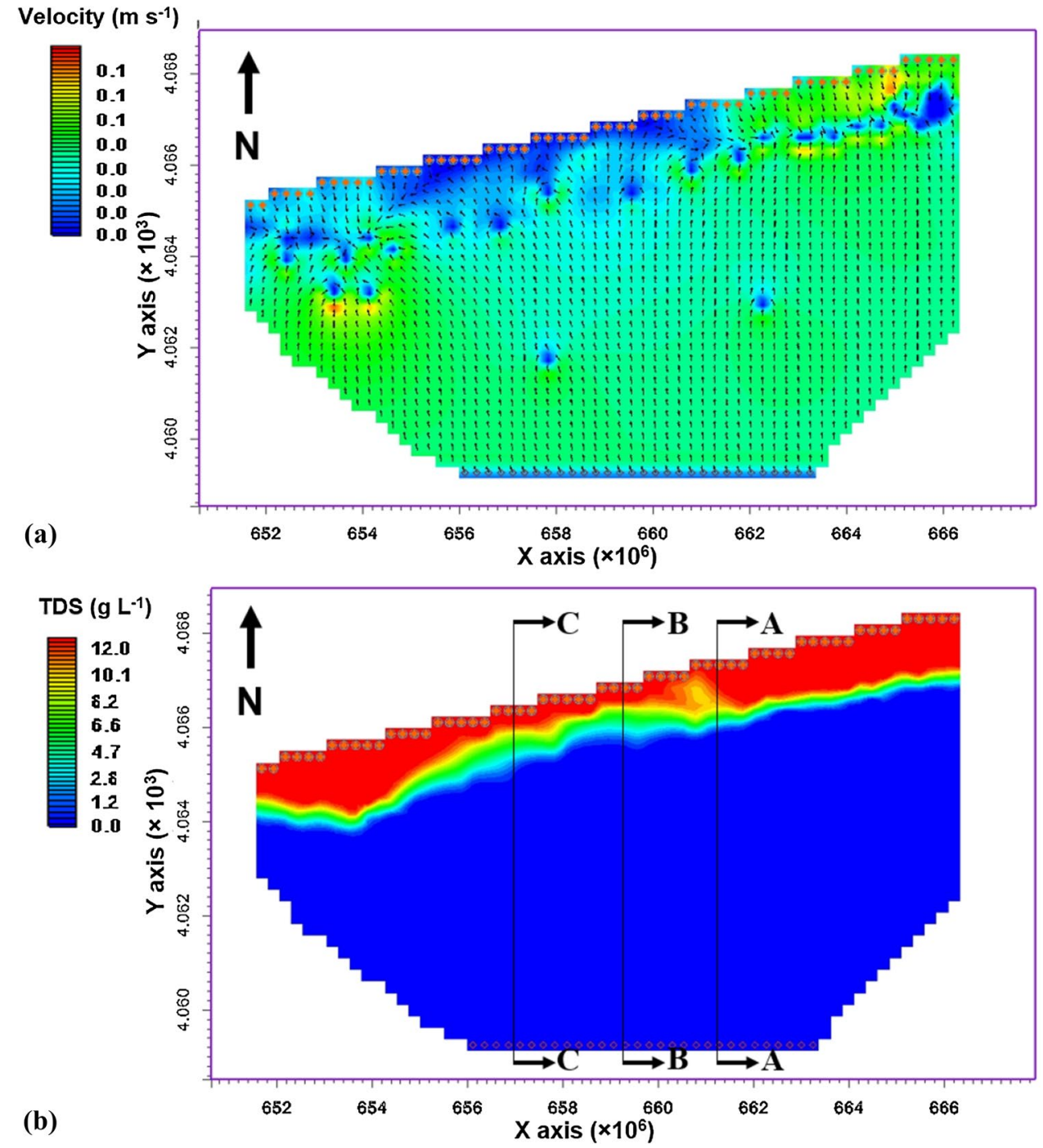


in northwestern and northeastern densely situated pumping wells have resulted in the intrusion of high level of TDS (TDS $>12 \mathrm{~g} \mathrm{~L}^{-1}$ ) into the freshwater aquifer (red areas in Fig. 4b). However, in mid-northern areas with less density of pumping wells the intrusion of water with a high level of TDS is significantly lower. This can also be attributable to the presence of clay and silt layers in the middle part of the aquifer (Fig. 2a) which acts as a protective layer, and thus the aquifer is less vulnerable in the middle part.

\section{Effects of SLR on SWI}

Figure 5 shows the cross-sectional TDS profile along sections A-A, B-B and C-C shown in Fig. 4b. The lengths of these profiles are, respectively, $5.6 \mathrm{~km}, 5.4 \mathrm{~km}$, and $5 \mathrm{~km}$, with depths varying from 15 to $20 \mathrm{~m}$. As shown in Fig. 4, in section $\mathrm{A}-\mathrm{A}$ the low anisotropy of the hydraulic conductivity led to a thin transition zone. The increased hydraulic gradient caused by SLR results in a higher advancement of seawater wedge toe and saturated zone. These changes in toe location are illustrated in Fig. 5 and compared with the HC system in a shallow confined aquifer. As shown in Fig. 5, an SLR of $1 \mathrm{~m}$ resulted in 30-40 m and 40-60 m advancements of iso-concentration line 50\% (T50) and iso-concentration line $10 \%$ (T10), respectively.

These results are in agreement with Hussain and Javadi's (2016) findings reporting about $75 \mathrm{~m}$ and $100 \mathrm{~m}$ intrusion of T50 and T10, respectively, for a hypothetical aquifer with shoreline slopes less than 5\% and HC boundary conditions. These minor differences indicate the direct proportionality between the aquifer's depth and SWI during an ISLR. Permeability variations from the east (section $\mathrm{A}-\mathrm{A}$ ) with an average permeability of $T=1.6 \mathrm{~m}^{2} / \mathrm{s}$ to the west (section $\mathrm{C}-\mathrm{C}$ ) with an average permeability of $\mathrm{T}=3.1 \mathrm{~m}^{2} / \mathrm{s}$ led to a $\Delta T 50$ of $32 \mathrm{~m}$ and $39 \mathrm{~m}$, respectively. Variation of aquifer's depth from $15 \mathrm{~m}$ (section A-A) to $18 \mathrm{~m}$ (section B-B) resulted in $7 \%$ increase in $\Delta T 50$ (Fig. 6). So, the aquifer vulnerability to saltwater intrusion increases from east to west.

The greatest T50 intrusion was due to variations in recharge rates. Whenever the pumping rates were set constant and recharge rate decreased from 761 to $500 \mathrm{~mm} /$ year, the further migration of T50 is $65 \mathrm{~m}$ due to $1 \mathrm{~m} \mathrm{SLR}$.

\section{Impact of SLR on aquifer's hydraulic head and freshwater volume}

To assess the effects of variation in groundwater level on total freshwater volume (considered as water with TDS $<250 \mathrm{mg} \mathrm{L}^{-1}$ ) is calculated as percentage of the total number of cells in the SEAWAT model (combined volume of all freshwater, brackish water, and saline water) by the end of year 2100 (Figs. 3 and 7). Regarding the variation of the porosity throughout aquifer, $1 \mathrm{~m}$ SLR (parabolic increase) causes $5.6 \%$ to $6.8 \%$ depletion of the freshwater volume by the end of the year 2100 in the HC system.

\section{Transient movement of saltwater wedge toe}

To assess the transient saltwater wedge toe movement during SLR, the location of T50 was determined by considering $1 \mathrm{~m}$ SLR at the sea boundary. Figure 8 shows the transient migration of the T50 in section B-B for different ISLR scenarios with different transmissivities and recharge rates. As shown in Fig. 2a, Talar aquifer near the study area is semiconfined with a low specific yield; hence, the overshot has less effect on SWI due to the increase in transmissivity during the ISLR (Ketabchi et al. 2016). After the ISLR, saltwater intruded into the unsaturated zone and increased the permeability of aquifer near the seaside, while the GSLR increased the seawater and freshwater level and resulted in a greater SWI.

The movement rate is the highest after the GSLR and reduces after 48 years. The time to reach the peak SWI rate for recharge rates of $761 \mathrm{~mm}_{\text {year }}{ }^{-1}$ and $1000 \mathrm{~mm}_{\text {year }}{ }^{-1}$ is about 48 and 32 years, respectively (Fig. 8). The delay in the peak of the SWI rate increased with increasing horizontal hydraulic conductivity and recharge rate. For example, for a transmissivity value $T=1.6 \mathrm{~m}^{2} / \mathrm{s}$ and recharge rate $R=761 \mathrm{~mm} /$ year the peak is delayed to 48 years. Thus, the estimated time to reach equilibrium in high permeability was considerably low during ISLR. Regarding the high gradients in this case, the volume of saltwater intrusion also is low. The total area under the curves in Fig. 8 represents the SWI length for each scenario. As shown, the maximum length is about $42 \mathrm{~m}$ for $R=761 \mathrm{~mm}_{\text {year }}{ }^{-1}$ and $T=1.6 \mathrm{~m} / \mathrm{s}^{2}$.

Although the transient location of T50 during SLR is mostly sensitive to recharge rates of the aquifer, the inland boundary condition has a significant impact on the SWI rate. Thus, the transient movement of T50 for Talar aquifer is compared with head-controlled and flux-controlled (FC) systems. As shown in Fig. 9, the progress of T50 in the ISLR follows the same trend in the HC system. Thus, the assumption of $\mathrm{HC}$ system as a simplification can be implemented for Talar aquifer, which causes the predicted SWI to be relatively overestimated.

\section{Model validation}

The ratio of SWI variation after ISLR to aquifer's length $(L)$ and ratio of SLR to aquifer's depth $(W)$ for several aquifers with land surface and shoreline slopes of less than $1 \%$ are presented in Table 2. The presented values in Table 2 are based on the numerical solutions for hypothetical and real aquifers located at the Nile, Mediterranean, and Gaza aquifer (Werner and Simmons 2009; Sefelnasr and Sherif 2014; Abd-Elhamid et al. 2016; Ketabchi et al. 2016). As shown 

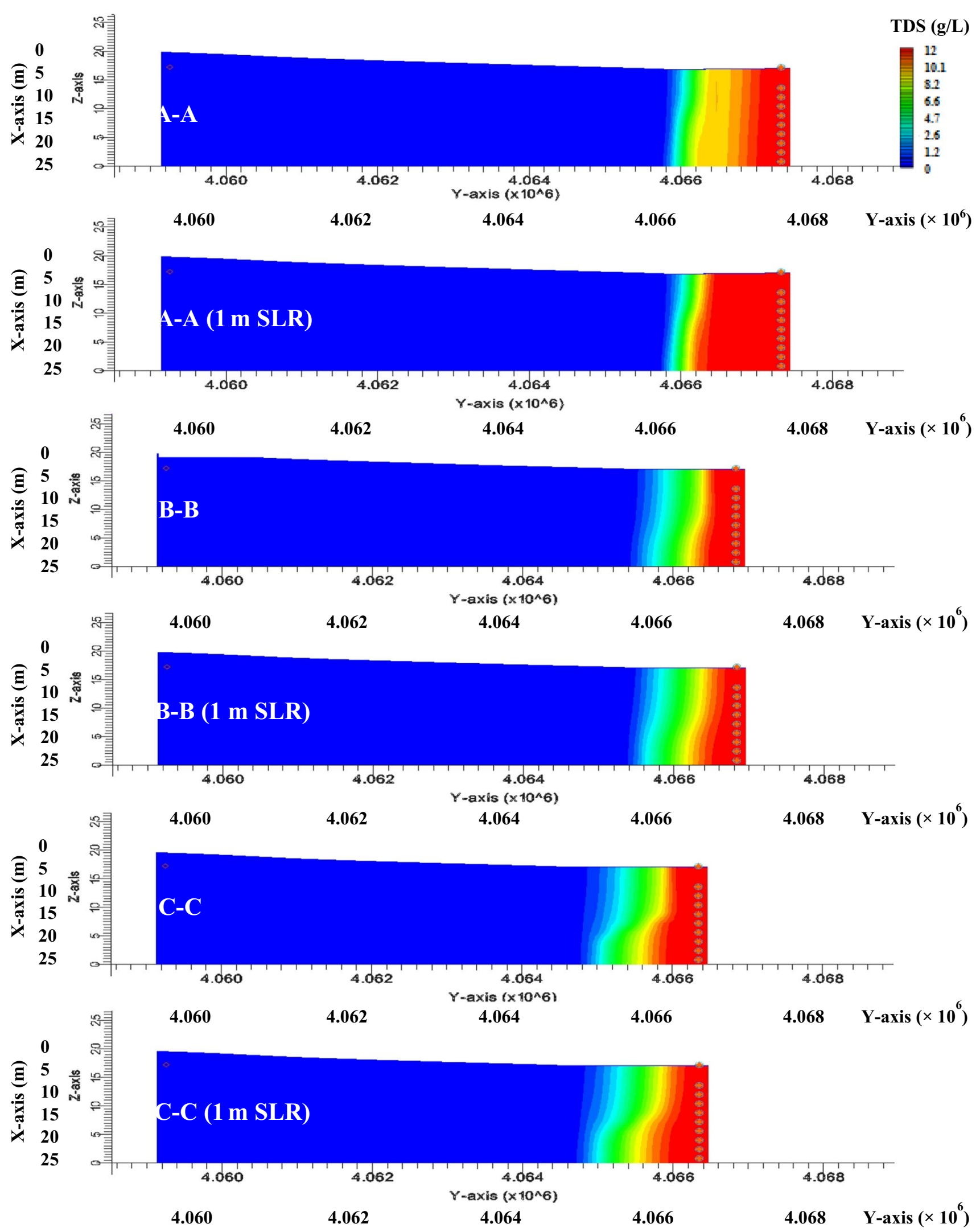

Fig. 5 Shape of the transition zone and salinized area after and before $1 \mathrm{~m} \mathrm{SLR}$ 
Fig. 6 Variation of T50 after $1 \mathrm{~m}$ SLR for different cross sections of aquifer

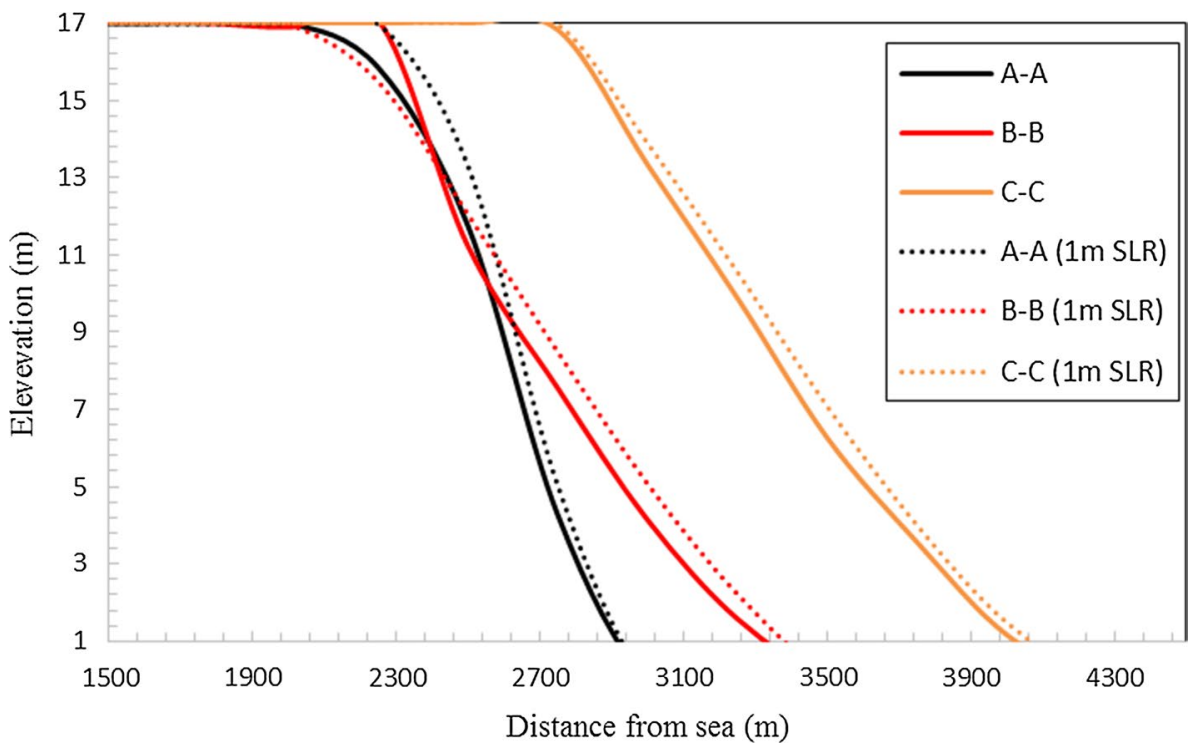

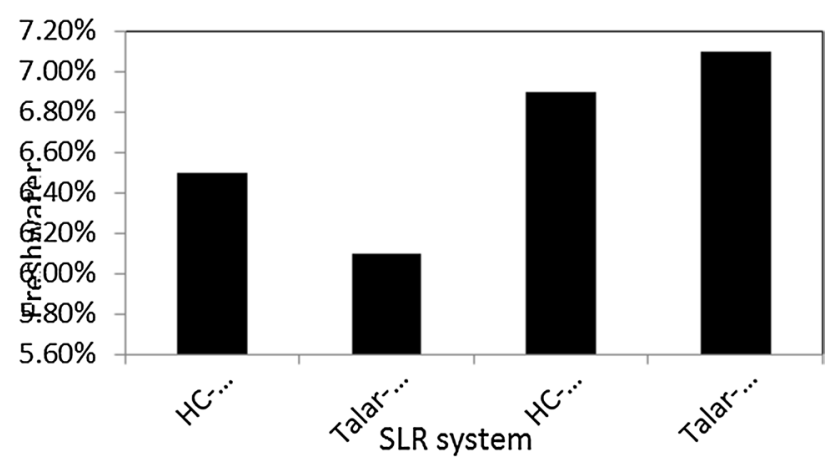

Fig. 7 Decline in aquifer's freshwater volume due to a $1 \mathrm{~m}$ SLR in Table 2, the ISLR impact on toe location is significant for the HC boundary system with a high value of aquifer length.

To obtain a high correlation coefficient between input and output data, different non-dimensional parameters were examined.

The number of tree parameters is determined by the trial-and-error procedure. The tree with low Nash-Sutcliffe error is applied for prediction. The decision tree calculates the RMSE for each iteration and updates itself with new samples generated by the simulation model. While RMSE is less than the threshold value (0.072), the training process is stopped and parameters are determined for current samples. The decision tree with the best efficiency for testing data has a depth of 2 and number of nodes 7 , respectively. In the training step, the unpruned tree shows a high correlation coefficient (0.96) for training data, while in the validation step the pruned tree indicates a high correlation coefficient (0.92). The non-dimensional SLR
Fig. 8 Displacement rate of T50 in section B-B due to $1 \mathrm{~m}$ ISLR with different transmissivities and recharge rates

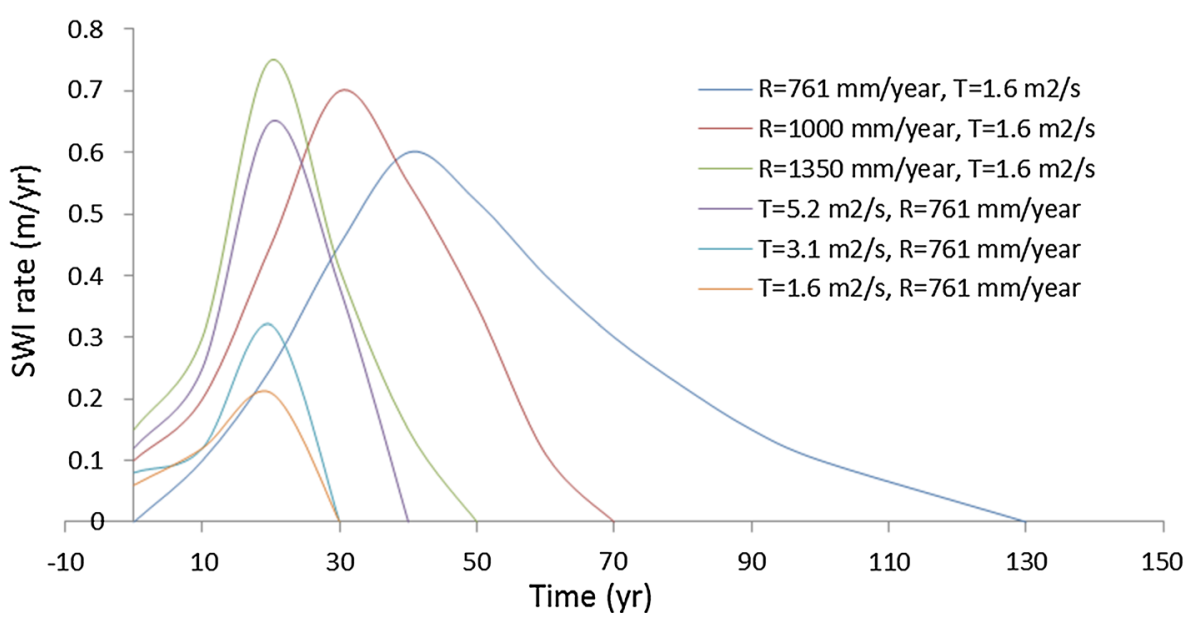




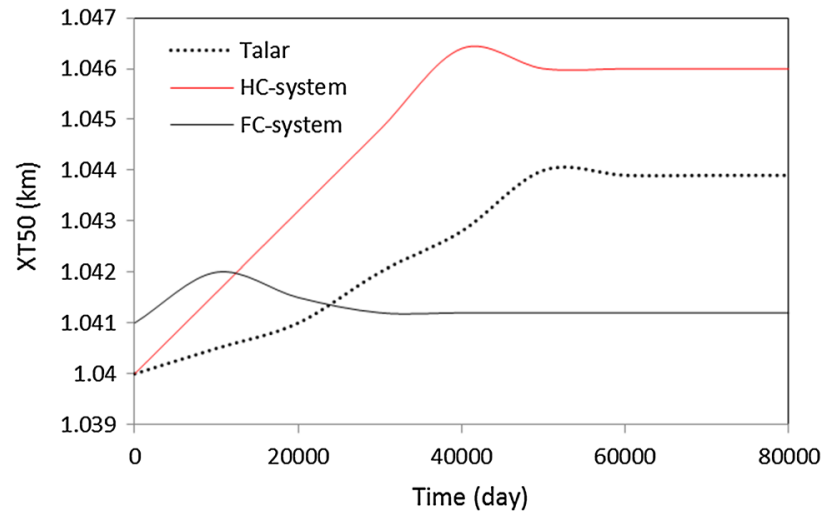

Fig. 9 Transient location of T50 in Talar aquifer compared to aquifers with head-controlled (HC) and flux-controlled (FC) boundary conditions

$(\mathrm{SLR} / W)$ and SI $(\Delta T 50 / L)$ are considered as input and output of the tree model, respectively (Table 2).

The values of the optimal depth and nodes of generated M5 tree in the WEKA software were 2 and 7, respectively. The linear regression relations created by M5 tree are presented in Table 3.

The positive coefficients of SLR* in M5 equations confirm that the input SLR* has a direct impact on $\Delta T 50^{*}$. Moreover, the location of $T 50$ in the $\mathrm{HC}$ system is more sensitive to the variation of SLR value than the FC system. Figure 10 illustrates the plot of observed vs predicted $\Delta T 50^{*}$ using M5 equations.

As shown in Fig. 9, the training samples are concentrated near the best regression line with an $R$ value of 0.85 . Moreover, the error criteria of $\mathrm{RMSE}=0.018$ and $\mathrm{MAE}=0.014$ indicate that the proposed M5 tree is accurate. However, the correlation is less for the higher $\Delta T 50^{*}$ resulting from high SLR values. To validate the SEAWAT model results, the value of $\Delta T 50$ was calculated using the proposed tree model. The M5 tree estimated $\Delta T 50$ values of $48 \mathrm{~m}$ and $10.42 \mathrm{~m}$ for Talar aquifer with $\mathrm{HC}$ and FC boundary conditions, respectively. Thus, the SWI of Talar aquifer during ISLR was mostly matched by the HC condition.

Table 3 Regression relations provided by M5 tree

\begin{tabular}{ll}
\hline Conditions & Equation \\
\hline If $\mathrm{HC}^{\text {and } \mathrm{SLR}^{*}>0.002, \text { then }}$ & $\Delta T 50^{*}=2.839 \mathrm{SLR}^{*}+0.205$ \\
If $\mathrm{HC}$ and $\mathrm{SLR}^{*}>0.002$, then & $\Delta T 50^{*}=2.74 \mathrm{SLR}^{*}+0.108$ \\
If $\mathrm{FC}$ and $\mathrm{SLR}^{*}>0.002$, then & $\Delta T 50^{*}=1.0966 \mathrm{SLR}^{*}+0.0012$ \\
If $\mathrm{FC}$ and $\mathrm{SLR}^{*}>0.002$, then & $\Delta T 50^{*}=1.080 \mathrm{SLR}^{*}+0.0001$ \\
\hline
\end{tabular}

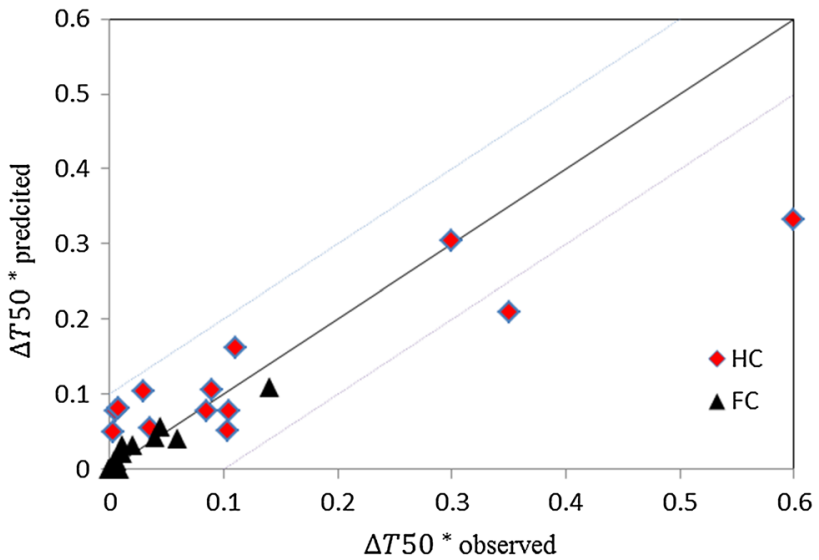

Fig. 10 Comparison between the predicted and the observed $\Delta T 50^{*}$ using M5 equations

\section{Conclusions}

In this study, the effects of $1 \mathrm{~m}$ ISLR and GSLR were assessed on groundwater quality in the Talar aquifer, with slopes of 0.06 and average depth of $9 \mathrm{~m}$ below the mean sea level. A variable-density flow model was developed and calibrated by means of six observation wells to predict salinity and groundwater level from 2015 to 2100 . Finally, using a M5 tree model the result of SWI during SLR is compared with previous work for land surface and shoreline slopes less than $1 \%$. The results of SWI after the $1 \mathrm{~m}$ ISLR indicate that if the sea level is rapidly increased from $11 \mathrm{~m}$ to $12 \mathrm{~m}$, the saltwater wedge toe advances about $35 \mathrm{~m}$ to the aquifer. The results also indicate that under different recharge rates the saltwater wedge toe progresses no longer than $45 \mathrm{~m}$. The difference in SWI by $93 \%$ variation of permeability and aquifer depth is $4 \%$ and $32 \%$, respectively. Increasing the recharge rate results in delaying the peak value of SWI in the GSLR scenario, and the required time to reach this maximum SWI is about 48 years. Therefore, neglecting the impact of recharge rate during GSLR results in a significant underestimation of transient SWI. While both GSLR and ISLR show a significant impact on the SWI trend, the effect of SLR has a low influence on groundwater extraction scenarios, as it results in only $6.5 \%$ depletion of freshwater volume. M5 tree with the 0.85 correlation coefficient between observed and predicted data suggests $\Delta T 50^{*}=2.74 \mathrm{SLR}^{*}+0.108$ relation between SLR and SWI for Talar aquifer. In conclusion, the main contribution of this study is the assessment of $1 \mathrm{~m}$ ISLR and GSLR effects on SWI and freshwater resources in a real case study. However, the results of the current study are valid for shallow coastal aquifers and cannot be generalized to deep aquifers. The effect of SLR on freshwater resources and its influence on optimal management scenario have potential opportunities for future studies. 
Acknowledgments The authors wish to thank all who assisted in conducting this work.

\section{References}

Abd-Elhamid HF, Javadi AA (2011) Impact of sea level rise and over-pumping on seawater intrusion in coastal aquifers. J Water Clim Change 1:19-28. https://doi.org/10.2166/wcc.2011.053

Abd-Elhamid H, Javadi A, Abdelaty I, Sherif M (2016) Simulation of seawater intrusion in the Nile Delta aquifer under the conditions of climate change. Hydrol Res 47(6):1198-1210

Abd-Elhamid H, Abdelaty I, Sherif M (2019) Evaluation of potential impact of Grand Ethiopian Renaissance Dam on seawater intrusion in the Nile Delta aquifer. Int J Environ Sci Technol 16(5):2321-2332

Anderson F, Al-Thani N (2016) Effect of sea level rise and groundwater withdrawal on seawater intrusion in the Gulf Coast aquifer: implications for agriculture. J Geosci Czech 4(04):116

Brunner P, Simmons CT (2012) HydroGeoSphere: a fully integrated, physically based hydrological model. Groundwater 50(2):170-176

Carretero S, Rapaglia J, Bokuniewicz H, Kruse E (2013) Impact of sea-level rise on saltwater intrusion length into the coastal aquifer, Partido de La Costa, Argentina. Cont Shelf Res 61:62-70

Chang SW, Clement TP, Simpson MJ, Lee KK (2011) Does sea-level rise have an impact on saltwater intrusion? Adv Water Resour 34:1283-1291. https://doi.org/10.1016/j.advwatres.2011.06.006

Chesnaux R (2016) Closed-form analytical solutions for assessing the consequences of sea-level rise on unconfined sloping island aquifers. Global Planet Change 139:109-115

Colombani N, Osti A, Volta G, Mastrocicco M (2016) Impact of climate change on salinization of coastal water resources. Water Resour Manag 30(7):2483-2496

Diersch HJG (2005) FEFLOW software-finite element subsurface flow and transport simulation system-reference manual. WAS $\mathrm{GmbH}$, Berlin

Fatemi E, Ataie-Ashtiani B (2008) Simulation of seawater intrusion effect on contaminant transport in coastal aquifer of Tallar. In: 4th National congress of civil engineering. Tehran University, Iran

Ferchichi H, Hamouda MB, Farhat B, Mammou AB (2018) Assessment of groundwater salinity using GIS and multivariate statistics in a coastal Mediterranean aquifer. Int J Environ Sci Technol 15(11):2473-2492

Frank E, Hall M, Trigg L, Holmes G, Witten IH (2004) Data mining in bioinformatics using Weka. Bioinformatics 20(15):2479-2481

Garner SR (1995) Weka: the waikato environment for knowledge analysis. In: Proceedings of the 2nd New Zealand computer science research students conference. Hamilton, New Zealand, pp 57-64

Green NR, MacQuarrie KTB (2014) An evaluation of the relative importance of the effects of climate change and groundwater extraction on seawater intrusion in coastal aquifers in Atlantic Canada. Hydrogeol J 22(3):609-623

Guo W, Langevin CD (2002) User's guide to SEAWAT; a computer program for simulation of three-dimensional variable-density ground-water flow. US Geological Survey Open-File Report 01-434, p 79

Harbaugh AW (2005) MODFLOW-2005, the US Geological Survey modular ground-water model: the ground-water flow process. US Department of the Interior, US Geological Survey, Reston, pp 6-A16

Hastie T, Tibshirani R, Friedman J (2009) The elements of statistical learning: data mining, inference, and prediction. Springer, New York. https://doi.org/10.1007/978-0-387-84858-7
Hussain MS, Javadi AA (2016) Assessing impacts of sea level rise on seawater intrusion in a coastal aquifer with sloped shoreline boundary. J Hydro-Environ Res 11:29-41

IPCC (2013) Climate Change 2013: the physical science basis. In: Stocker TF, Qin D, Plattner GK, Tignor M, Allen SK, Boschung J, Nauels A, Xia Y, Bex V, Midgley PM (eds) Contribution of Working Group I to the fifth assessment report of the intergovernmental panel on climate change. Cambridge University Press, Cambridge, p 1535

Ketabchi H, Mahmoodzadeh D, Ataie-Ashtiani B, Werner AD, Simmons CT (2014) Sea-level rise impact on fresh groundwater lenses in two-layer small islands. Hydrol Process 28(24):5938-5953

Ketabchi H, Mahmoodzadeh D, Ataie-Ashtiani B, Simmons CT (2016) Sea-level rise impacts on seawater intrusion in coastal aquifers: review and integration. J Hydrol 535:235-255

Khairy H, Janardhana MR (2016) Impact of the geological setting and anthropogenic activities on groundwater salinization: a case study on semi confined coastal aquifer in Mazandaran province northern Iran. J Appl Geochem 18(2):203-214

Kiraly L (1985) FEM301-a three dimensional model for groundwater flow simulation. NAGRA Technical report, 84-49, p 96

Kuchaksaraei BS, Fatemi SMR, Danehkar A, Jozi SA, RamezaniFard E (2019) New guidelines for the identification and selection of coastal-marine representative areas for Hormozgan Province, Iran. Int J Environ Sci Technol 16(12):8061-8072

Langevin CD, Dausman AM (2005) Numerical simulation of saltwater intrusion in response to sea-level rise. In: Proceedings of the EWRI '05 world water and environmental resources congress. ASCE, Anchorage, pp 1-8

Li L, Barry DA, Jeng DS (2001) Tidal fluctuations in a leaky confined aquifer: dynamic effects of an overlying phreatic aquifer. Water Resour Res 37(4):1095-1098

Loáiciga HA, Pingel TJ, Garcia ES (2012) Sea water intrusion by sea - level rise: scenarios for the 21 st century. Groundwater 50(1):37-47

Lu C, Xin P, Li L, Luo J (2015) Seawater intrusion in response to sea-level rise in a coastal aquifer with a general-head inland boundary. J Hydrol 522:135-140

Michael HA, Russoniello CJ, Byron LA (2013) Global assessment of vulnerability to sea-level rise in topography-limited and recharge-limited coastal groundwater systems. Water Resour Res 49(4):2228-2240

Morgan LK, Bakker M, Werner AD (2015) Occurrence of seawater intrusion overshoot. Water Resour Res 51(4):1989-1999

Pillai K, Etemad-Shahidi A, Lemckert C (2017) Wave overtopping at berm breakwaters: experimental study and development of prediction formula. Coast Eng 130:85-102

Pool M, Post VE, Simmons CT (2014) Effects of tidal fluctuations on mixing and spreading in coastal aquifers: homogeneous case. Water Resour Res 50(8):6910-6926

Quinlan JR (2014) C4. 5: programs for machine learning. Elsevier

Ranjbar A, Ehteshami M (2019) Spatio-temporal mapping of salinity in the heterogeneous coastal aquifer. Appl Water Sci 9(2):32

Ranjbar A, Mahjouri N (2019) Multi-objective freshwater management in coastal aquifers under uncertainty in hydraulic parameters. Nat Resour Res. https://doi.org/10.1007/s11053-019-09585 $-3$

Sefelnasr A, Sherif M (2014) Impacts of seawater rise on seawater intrusion in the Nile Delta aquifer, Egypt. Groundwater 52(2):264-276

Sharip Z, Yusoff FM, Jamin A (2019) Seasonal water quality and trophic status of shallow lentic waters and their association with water levels. Int J Environ Sci Technol 16(8):4851-4862

Stigter TY, Nunes JP, Pisani B, Fakir Y, Hugman R, Li Y, Monteiro JP (2014) Comparative assessment of climate change and its 
impacts on three coastal aquifers in the Mediterranean. Reg Environ Change 14(1):41-56

Uddameri V, Singaraju S, Hernandez EA (2014) Impacts of sea-level rise and urbanization on groundwater availability and sustainability of coastal communities in semi-arid South Texas. Environ Earth Sci 71(6):2503-2515

Vermeer M, Rahmstorf S (2009) Global sea level linked to global temperature. Proc Natl Acad Sci 106(51):21527-21532

Voss CI, Provost AM, (2010) SUTRA: a model for saturated-unsaturated, variable density groundwater flow with solute or energy transport. USGS Water-Resources Investigations Report, 02-4231, U.S. Geological Survey, Reston

Watson TA, Werner AD, Simmons CT (2010) Transience of seawater intrusion in response to sea level rise. Water Resour Res. https:// doi.org/10.1029/2010wr009564

Webb MD, Howard KW (2011) Modeling the transient response of saline intrusion to rising sea levels. Groundwater 49(4):560-569

Werner A, Simmons CT (2009) Impact of sea-level rise on sea water intrusion in coastal aquifers. Groundwater 47(2):197-204

Werner AD, Bakker M, Post VE, Vandenbohede A, Lu C, AtaieAshtiani B, Barry DA (2013) Seawater intrusion processes, investigation and management: recent advances and future challenges. Adv Water Resour 51:3-26

Xiao H, Tang Y (2019) Assessing the "superposed" effects of storm surge from a Category 3 hurricane and continuous sea-level rise on saltwater intrusion into the surficial aquifer in coastal eastcentral Florida (USA). Environ Sci Pollut R 26:21882-21889

Xiao H, Wang D, Medeiros SC, Hagen SC, Hall CR (2018) Assessing sea-level rise impact on saltwater intrusion into the root zone of a geo-typical area in coastal east-central Florida. Sci Total Environ 630:211-221

Yang J, Graf T, Ptak T (2019) Combined influence of weir construction and sea-level rise on freshwater resources of a coastal aquifer in northern Germany. Hydrogeol J 27:2695-2705

Zheng C, Wang MC (1999) MT3DMS - a modular three-dimensional multispecies transport model for simulation of advection, dispersion and chemical reactions of contaminant in ground-water systems; documentation and user's guide. US Army Corps of Engineers Contract Report SERDP-99-1; Vicksburg, Mississippi, p 169 